\title{
A PROPÓSITO DE «EL CONCEPTO DE ESTABILIDAD DE LOS SISTEMAS POLÍTICOS», DE ERNESTO GARZÓN VALDÉS *
}

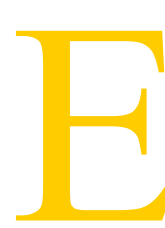

n el tema de las relaciones entre la legitimidad y la estabilidad, los filósofos contemporáneos han asumido dos posiciones: un grupo piensa que estos conceptos están estrechamente asociados, al punto que resulta casi imposible establecer diferencias claras entre ellos. Otro grupo, postula la necesidad de una clasificación rígida y exacta, que distinga, definitivamente, entre uno y otro. Garzón inaugura una posición diferente de ambas corrientes: mientras sostiene la tesis de que la legitimidad no es una condición suficiente, ni necesaria para la estabilidad, acepta, de cara a la realidad política de nuestro tiempo, las dificultades instrumentales y las ambigüedades que conlleva la empresa de diferenciarlas analíticamente.

\section{La ambigüedad de las clasificaciones}

En esto de ponerse de acuerdo sobre quién es calvo y cuándo hace mal tiempo, nada resulta fácil y mucho menos perfectamente claro. Pero en realidad ¿por qué tendría que ser así, en un mundo tantas veces difícil y confuso?... Por esta razón creo que las limpias opciones dicotómicas propuestas por Goodman (maestro en esas artes) y citadas en pág. 95, representan un falso dilema. La mejor prueba de mi afirmación se encuentra en el agudo trabajo que Garzón nos ofrece; y aunque con elegante estilo el autor acepta una de las opciones de Goodman, cuida muy bien su espalda con un cauto condicional: «Siendo así las cosas»... lo que deja abierta la posibilidad de que sean de otro modo, en cuyo caso tal vez la elección sería distinta.

Analizado el trabajo, sin duda quedan en el asunto cosas suficientemente oscuras como para que aún sea intrigante; pero esto no se debe al fracaso del autor en su intento por clarificarlo, sino por el contrario se debe a que tuvo éxito en la empresa por

* Ernesto Garzón Valdés, El concepto de estabilidad de los sistemas políticos, Ed. Centro de Estudios Constitucionales (Col. Cuadernos y Debates). Madrid, 1987, 111 págs. 
tornarlo lo suficientemente claro como para que sea racionalmente discutible. Como con el tiempo, como con la calvicie, lo suficientemente claro suele confundirse con lo suficientemente oscuro.

Estas consideraciones sirven para que, una vez más, se reflexione acerca de las grandes dificultades que trae aparejado cualquier intento de trazar una línea divisoria que sirva de criterio clasificatorio. Toda pretensión de lograr un trazo inequívoco es ilusoria, y siempre se pierden cosas en el intento. Sin embargo, estos son los esfuerzos que van haciendo posible un escenario cada vez más racional como marco de la discusión filosófica.

\section{La estabilidad como propiedad disposicional}

La tesis central de la independencia entre la legitimidad y la estabilidad atraviesa el trabajo de Garzón, y esta tesis posee un indiscutible valor tanto en el campo estrictamente filosófico y analítico como en el político, terreno este último donde la confusión de ambas esferas produce consecuencias tan indeseables como la de suponer que la estabilidad es un valor en sí misma, y como tal debe ser irrestrictamente salvaguardada.

El recurso metodológico empleado por Garzón, consiste en deslindar la esfera de la legitimidad, a la que considera como una propiedad ética del sistema, de la esfera de la estabilidad a la que le asigna el carácter de propiedad disposicional del sistema. Este deslinde coloca a cada una de estas propiedades en un diferente entorno metodológico de justificación.

El considerar a la estabilidad como una propiedad disposicional, ofrece la ventaja de dotarla de una cierta previsibilidad (pág. 14). En este punto convendría señalar que el tipo de predicción que puede efectuarse en un terreno como el de la estabilidad, partiría de una probabilidad a priori, que luego se irá modificando con sucesivas informaciones que serán las que marquen la tendencia (enfoque bayesiano) ${ }^{1}$.

Los momentos en que se efectúan los tests de estabilidad reciben el nombre de $t_{\mathrm{i}}$ con i desde 1 hasta n; y el momento que se

\footnotetext{
${ }^{1}$ En el enfoque bayesiano la inferencia de las ocurrencias en un $t_{n+1}$ a partir de lo ocurrido en $t_{1}$, $t_{2} \ldots . . . t_{n}$, consiste en un sucesivo tránsito de una probabilidad anterior, a una ulterior. Cada paso en ese tránsito no es solamente mecánico, sino que supone una toma de decisión respecto de todos los elementos implicados en la inferencia (predictores utilizados, niveles de medición, calidad de las pruebas, etc.) con el fin de aumentar cada vez la previsibilidad de los sucesos en $\mathrm{tt}_{\mathrm{n}+1}$.
} 
desea predecir es el llamado $t_{n 1+} 1$. Los tests consisten en medir la capacidad del sistema (S*) para reaccionar en forma tal que sus cambios sean explicación de su regla de reconocimiento $\left(\mathrm{R}_{\mathrm{r}}\right)$, en las circunstancias que me inclino a llamar $\mathrm{C}_{\mathrm{i}}$, con $\mathrm{i}$ de 1 hasta $\mathrm{n}$, en lugar de $\mathrm{C}$, porque no son constantes. Esto conforme a $\mathrm{D}_{3}$ de págs. 31-32.

Consideradas así las circunstancias $\left(\mathrm{C}_{1}\right)$ forman parte inevitable en la previsión de la estabilidad de $\mathrm{S}^{*}$ para cualquier $\mathrm{t}_{\mathrm{n}^{+}}$1. Esto es así porque a lo largo del tiempo, tales circunstancias van poniendo a prueba diferentes capacidades que configuran la propiedad de disposición de $\mathrm{S}^{*}$ a la estabilidad. Estas pruebas corrigen, bayesianamente hablando, la probabilidad anterior y la convierten en una posterior, dando lugar a mejores predicciones. Garzón sostiene en el trabajo que tales $\mathrm{C}_{\mathrm{i}}$ son instancias de confirmación (o no) de la disposición de $\mathrm{S}^{*}$ a reaccionar $\mathrm{R}_{\mathrm{r}}$. En los $\mathrm{C}_{\mathrm{i}}$ llamados «casos límites», se ponen a prueba capacidades especiales del $S^{*}$ para reaccionar $R_{r}$, tales como: a) capacidad para resolver contradicciones, b) capacidad para satisfacer expectativas y c) capacidad para evitar las mutaciones mediante la explicación de la $\mathrm{R}_{\mathrm{r}}$ (págs. 33-38).

En esta revisión le otorgo especial importancia a la condición b), ya que ella apela a la «capacidad» de rendimiento del gobierno a fin de no «frustrar las expectativas». Tanto las expectativas como la capacidad de rendimiento del gobierno están animadas por un valor ético (esfera de la legitimidad) que se filtra en la función de predicción. Este hecho no se escapa a Garzón; pero a mi juicio él minusvalora la erosión que tal circunstancia produce en su teoría acerca de la relación entre legitimidad y estabilidad.

Si la crisis de legitimidad participa en la función predictora del nivel de estabilidad de un $\mathrm{S}^{*}$ para un $\mathrm{t}_{\mathrm{n}+} 1$ cualquiera, algún vínculo tiene que ligar a la legitimidad, o a su falta, con la estabilidad, ya que no hay predicción posible entre condiciones totalmente independientes.

Cabría entonces pensar que aunque las esferas de la estabilidad y la legitimidad son en efecto diferentes, y ambas tienen métodos de validación también distintos (la una requiere de pruebas de origen empírico, mientras que la otra utiliza los principios de la ética normativa como base argumental), sin embargo no configuran condiciones independientes. Para aceptar esto basta con preguntarnos ¿qué efecto tendría el eliminar «la legitimidad»o «la crisis de legitimidad» en la función predictora de la estabilidad?

Tendríamos necesariamente que responder que la predicción se empobrecería (bayesianamente hablando); en consecuencia 
habrá que admitir que por alguna razón, y de algún modo especial, estabilidad y legitimidad se vinculan.

\section{Una relación diferente}

Cuando se considera la estabilidad como una propiedad disposicional, se abre un horizonte muy amplio para efectuar eventuales predicciones sobre la misma, empleando el recurso de la observación y pruebas de la capacidad de $\mathrm{S}^{*}$ para reaccionar $\mathrm{R}_{\mathrm{r}}$. (En la Parte II del trabajo se pone exitosamente a prueba sobre hechos ya ocurridos, la bondad de los elementos predictores elaborados). Sin embargo creo detectar que tal propósito se torna muy difícil de alcanzar apoyándose en la clasificación binaria escogida (1 ó 0), la cual permite expresar las combinatorias (1.0.0) (1.0.1) (1. 1.0) y (1.1.1) [prefiero esta nomenclatura a la empleada por Garzón, porque da mejor cuenta de la autonomía de las esferas: existencia, legitimidad, estabilidad]. Este carácter binario torna demasiado drástica la clasificación (cada propiedad o está presente o está ausente), e impide ver una relación tan sutil como la de «ser predictor de». Pero a su vez esta relación, cargada de fineza y de potencia teórica, sólo ha podido tornarse visible a partir de la perspectiva planteada por Garzón cuando considera la estabilidad como propiedad disposicional, y de ese modo la diferencia de la esfera de la legitimidad. Si se ensayan otras clasificaciones de mayor poder discriminante se verá que bajo ciertas circunstancias, la legitimidad tiene una presencia mayor en la función de predicción de la estabilidad, mientras que otras veces prácticamente desaparece.

La necesidad de considerar y caracterizar esta nueva relación: «formar parte de la función predictora de» entre legitimidad y estabilidad, no debe entenderse como un retorno indeseable a la confusión de ambas esferas y de sus respectivos métodos de análisis, sino como la respuesta obligada ante la presencia de este especial vínculo que las liga, vínculo que se torna claro cuando se considera a la estabilidad como una propiedad disposicional.

\section{Conclusión}

El trabajo de Garzón contiene muchas ideas importantes y de gran potencial para la discusión filosófica. Me he centrado en su tesis sobre las relaciones entre la legitimidad y la estabilidad no 
sólo porque la considero vertebral, sino por razones de inquietudes intelectuales profundas. Recibí el trabajo que estoy comentando mientras daba fin a un artículo que intenta efectuar la revisión crítica de las soluciones al dilema del Prisionero. Sentía una cierta melancolía al comprobar que las soluciones estables eran fatalmente no-cooperativas en lugar de ser cooperativas como yo hubiera deseado. Después de leer el trabajo de Garzón, veo que la estabilidad no siempre se encuentra donde uno piensa que legítimamente debería estar, y esto representa un bello desafío.

Volviendo a Goodman, citado por Garzón, no creo que la función del filósofo sea la de tornar aburrido lo que todavía es suficientemente oscuro como para ser intrigante, sino que es la de despertar el carácter intrigante que siempre se oculta tras lo que muchos consideran ya como irremediablemente aburrido.

Y en esto radica el nada banal éxito de Garzón con su trabajo.

\section{REFERENCIAS}

Savage, L. J., y otros (1970), The Foundations of Statistical Inference-A Discussion, London: Methuen \& CoLTD.

Togerson, W. S. (1958), Theory and Methods of Scaling. New York: John Wiley. 